\title{
REVIEW
}

\section{Current Management of Primary Immune Thrombocytopenia}

\author{
Drew Provan · Adrian C. Newland
}

To view enhanced content go to www.advancesintherapy.com

Received: July 29, 2015 / Published online: October 26, 2015

(C) The Author(s) 2015. This article is published with open access at Springerlink.com

\begin{abstract}
Primary immune thrombocytopenia is an autoimmune disorder of unknown cause affecting both children and adults. The low peripheral blood platelet count is caused by

largely because of the introduction of the thrombopoietin receptor agonists. Currently there are trials underway evaluating novel therapies for ITP that will become available over the next few years once the trials are complete.
\end{abstract} premature platelet destruction by self-reacting antibodies in addition to an impairment of platelet production. The disease is heterogeneous in its pathophysiology, clinical features and responses to treatment. To date, most of the treatments used have been immune-modulating drugs and these contribute to increased morbidity and mortality in patients. A new class of drugs, the thrombopoietin receptor agonists, has been developed for use in ITP. These have gone through randomised controlled trials in large numbers of patients with ITP. These drugs have high efficacy and are well tolerated. In addition, around $30 \%$ of patients receiving these drugs are able to stop them and maintain a safe or normal platelet count. Older treatments such as splenectomy are being used less than before,

D. Provan $(\varangle) \cdot$ A. C. Newland

Blizard Institute, Barts and the London School of Medicine and Dentistry, Whitechapel, London, UK e-mail: a.b.provan@qmul.ac.uk
Keywords: Eltrombopag;

Immune thrombocytopenia; ITP; Management; Romiplostim; Second-line therapy; Sustained responses; TPO receptor agonists

\section{INTRODUCTION}

Primary immune thrombocytopenia (ITP) is an acquired autoimmune disorder affecting both children and adults, characterised by a platelet count below $100 \times 10^{9} / 1 \quad[1,2]$. Clinical manifestations include petechiae, purpura, bruising, and overt bleeding. Previously, 'acute ITP' was used to describe a self-limited form of disease and 'chronic ITP' thrombocytopenia described the disease if is lasted for more than 6 months. In 2009 new terminology for ITP was agreed upon based on the duration of the disease. The new terms for ITP are: 'newly 
diagnosed' (from diagnosis until 3 months), 'persistent ITP' (3-12 months) and 'chronic ITP' (ITP lasting for more than 12 months) [2]. Chronic primary ITP in adults is slightly more common in women of childbearing age but the sex incidence is similar in patients over $60[2,3]$. The incidence of ITP in adults is around 4 per 100,000 people per year, with a UK prevalence of up to 24 per 100,000 people [4-6].

Bleeding is highly variable and there is great heterogeneity in primary ITP. Bleeding is most commonly mucocutaneous, involving gum bleeding, blood blisters in the mouth and menorrhagia. Major bleeding is not common if the platelet count is above $30 \times 10^{9} / 1$. The most serious form of bleeding, intracranial haemorrhage, is rare and is most often seen in older patients who have additional comorbidities and in patients who fail to respond to therapy [7]. The yearly risk of fatal haemorrhage is around 1.6-3.9\% [8]. This risk varies with age, at $0.4 \%$ per annum in those below the age of 40 years to $13 \%$ per annum over patients over 60 years of age.

The aims of this review are to provide a brief overview of ITP and its current management. The main emphasis of the review is on the recently introduced TPO receptor agonists focussing on published trial data. Both romiplostim and eltrombopag are discussed in detail, including recently published studies that show the unexpectedly high rate of sustained responses to these agents following their discontinuation.

\section{CLINICAL FEATURES}

Paediatric and adult ITPs are quite different in terms of their underlying pathophysiology and clinical outcomes. In children, ITP may follow a viral infection or immunisation. In most children the disease remits spontaneously by 6 months with little need for medical treatment. Around $15 \%$ of children will go on to develop chronic ITP.

In the adult form of the disease there is usually no prodrome. Instead, the patient may notice an increase in bruising, or petechiae. In many cases ITP in adults is picked up by chance when the patient has a full blood count for other reasons, for example, preoperatively. This is seen particularly in the elderly when nearly a third will be diagnosed by chance.

ITP in adults is extremely heterogeneous. Many patients have no clinical problems related to their thrombocytopenia even at very low platelet counts, while other patients may have bleeding from the outset and a study of practice in Europe over 1 year showed that $40 \%$ of patients had no bleeding at all despite low platelet counts and required no treatment [9]. The platelet count by itself is an unreliable predictor of clinical outcome. Many factors contribute towards the bleeding risk including age, comorbidities, medication, prior bleeding history and other factors not yet identified. In some patients an autoantibody may bind to a critical epitope on the platelet glycoprotein and interfere with platelet function. Autoantibodies reacting with glycoprotein (GP)IIb/IIIa may affect platelet aggregation; these are the most common autoantibodies seen in primary ITP [10]. Antibodies against GPIb/IX may impair platelet adhesion to the subendothelial matrix, thereby causing severe bleeding for the level of platelet count. Other autoantibodies including antiphospholipid antibodies are detected in up to $30 \%$ of patients with ITP. These may affect platelet and vascular function. Overall, however, despite the severity of the thrombocytopenia, severe bleeding is not common in ITP, in contrast with 
thrombocytopenia following chemotherapy or bone marrow failure [11].

\section{MANAGEMENT OF ADULT ITP}

ITP in adults is a disease with low morbidity and mortality. Most patients with ITP have few problems related to the thrombocytopenia but a minority may be resistant to treatment and have a platelet count that is chronically low. After the publication of the original American Society of Hematology guideline in 1996 [12] there was a tendency to treat most patients whose platelet count was $<30 \times 10^{9} / 1$. Most of the treatments available until fairly recently had significant side effects for many patients. Because of the immune suppression often used to treat ITP, patients are at increased risk of infection. A study of 152 consecutive adult ITP patients published by Portielje and colleagues showed that the treatments used contributed significantly to an increase in morbidity and mortality in their cohort [13]. Contrary to what might be expected, half of the deaths observed in the study were attributable to the treatment used rather than haemorrhage. MacMillan showed this to be a particular problem in patients who had failed splenectomy and required continuing immune suppressive therapy [7].

Patients with ITP who have low platelet counts bleed less than patients with aplastic anaemia or chemotherapy-induced thrombocytopenia at equivalent platelet counts. For this reason, in addition to the toxicities of the treatments used discussed earlier, there has been a relaxation in the platelet thresholds for treatment. The International Consensus Report [3] suggested not treating patients whose platelet counts were $>50 \times 10^{9} / 1$. At this platelet count most patients will have few symptoms or signs of
ITP. Patients whose platelet counts are lower may also require little treatment depending on their age, comorbidities and bleeding history. Overall the number of patients with ITP who are on no treatment has risen over the past decade whilst the number of patients receiving medical treatment has fallen.

The main aim of treatment is to achieve a safe platelet count for each patient on a case-by-case basis [14]. The intention is not to normalise the platelet count. In general, treatment is seldom required when platelets are greater than $20 \times 10^{9} / 1$. For patients with platelets less than $20 \times 10^{9} / 1$ treatment may be required but this depends on a full assessment of the patient including lifestyle, occupation, bleeding history, comorbidities and other factors.

Initial first-line treatment has remained unchanged for decades and comprises corticosteroids [15], IVIg [16, 17] and anti-D [18] in countries where the latter is available. Corticosteroids are cheap, raising platelet counts rapidly within 1-2 days in around 75\% of patients. However, long-term responses are seen in only $25 \%$ of patients. Side effects are extremely common and predictable. Currently available corticosteroids include prednisone, prednisolone, methylprednisolone and dexamethasone. Prednisolone has been used predominantly as first-line treatment rather than dexamethasone but recent studies of the latter suggest that the response rates are higher and prolonged remission is seen more commonly [19]. However, despite this, prednisolone remains the first-line corticosteroid of choice [3].

There have been several trials of IVIg in ITP since its first use in the mid-1980s. The response rate in ITP is similar to that of corticosteroids but the time to response is shorter, with a response normally seen within $24 \mathrm{~h}$ although 
most are transient rarely exceeding 3-4 weeks. Toxicities include headache, renal impairment and thrombosis.

Intravenous anti-D is effective in $80 \%$ patients with primary ITP and is suitable for those who are $\mathrm{Rh}(\mathrm{D})$ positive and have not undergone splenectomy. The infusion time is shorter than for IVIg and the donor pool from which it is derived is much smaller than that of IVIg. Anti-D has been shown to induce a longer response time than IVIg [20] and may also reduce the need for splenectomy [21].

\section{SECOND-LINE THERAPY}

If a patient fails to respond to first-line treatment or relapses following a response there may be a need to introduce a second-line treatment. These treatments include medical therapies and splenectomy. The medical treatments used as second-line therapy have undergone few randomised controlled trials and a systematic review covering nearly 700 patients showed that complete remission rates rarely exceed 15\% and few of the individual studies have sufficiently large numbers of truly refractory patients to make a definitive recommendation [22]. Most of these drugs are not licensed for ITP and have been chosen because of their efficacy in other autoimmune diseases or in post-solid organ transplant immune suppression. The recent International Consensus Report provides a list of second-line therapies placed in alphabetical order because there were insufficient data to rank the treatments in order of efficacy, apart from the thrombopoietin receptor agonists, which have undergone rigorous randomised trials [3].

The immunosuppressants azathioprine, ciclosporine and mycophenolate have shown most efficacy in adult ITP although most studies are small. These are in general small, open studies and response rates should be considered with some scepticism. Azathioprine produces complete responses in $45 \%$ of patients [23]. Ciclosporine has been shown to improve platelet counts in one study of $80 \%$, with $42 \%$ patients achieving a complete response [24, 25]. Durable remissions have been reported after ciclosporine has been stopped [25]. Side effects include fatigue, renal insufficiency, hypertension and neuropathy. Mycophenolate mofetil has been shown to be of value in ITP. This immunosuppressant is similar to azathioprine and ciclosporine and is an anti-proliferative agent [26]. An overall response rate of $78 \%$ has been reported. Interestingly, prolonged remissions of $25 \%$ have been reported in patients on mycophenolate [27].

Rituximab is been licensed for rheumatoid disease and has been used for some years in ITP with initial responses of $60 \%$ and durable responses of $15-20 \%$. However, there are safety issues with rituximab including progressive multifocal leucoencephalopathy (PML) and hypogammaglobulinaemia in addition to the lack of approval for its use in ITP [28-30]. A more recent randomised placebo controlled study using rituximab in the second-line setting demonstrated a much less favourable response, and although those who achieved CR on rituximab had a more durable response the benefits were small [31]. For these reasons rituximab usage will probably decline particularly with the wide availability of the newer TPO receptor agonists. Rituximab may be used at the standard dose $\left(375 \mathrm{mg} / \mathrm{m}^{2}\right)$ or low dose at $100 \mathrm{mg}$ weekly for 4 weeks [32]. Response to rituximab is generally seen after 1-2 weeks but in some patients a response may be seen up to 2 months after the last infusion $[28,30]$. 
Cyclophosphamide, an alkylating agent, has been used successfully in adult ITP. It can be given orally at $1-2 \mathrm{mg} / \mathrm{kg} / \mathrm{day}$ for up to 4 months or it may be given IV at $0.3-1 \mathrm{~g} / \mathrm{m}^{2}$ for between 1 and 3 doses every $2-4$ weeks. The reported response rate is $24-85 \%$ [33, 34].

Danazol is an attenuated androgen and is given orally at $200 \mathrm{mg}$ between two and four times per day. The response rate is around $60 \%$ [35]. Danazol may be more effective in older females and those patients who have not undergone splenectomy [35].

Dapsone is an anti-leprotic drug that has been used successfully in ITP. It is usually given at 75-100 mg/day orally. Responses may be seen in up to $50 \%$ patients [36]. Because of its risk in glucose-6-phosphate dehydrogenase deficiency, at-risk males should be screened for this before starting dapsone. It is however a very cheap form of treatment and is widely used in the developing world.

Splenectomy has been used as a second-line treatment for ITP for 100 years [37]. Following splenectomy there is an early response rate of $80 \%$ but over time relapses occur and the long-term response rate is closer to $66 \%$ [38-40]. Even if splenectomy fails to induce a complete remission, many patients may still experience a partial response to splenectomy with a platelet count that is higher than that before splenectomy [12, 41].

Since splenectomy is a surgical procedure there are risks associated with this including bleeding, thrombosis and infection. Complication rates are highly variable depending on a number of factors $[13,38,39$, $42,43]$ and are higher in older patients [44] and in open splenectomy compared to laparoscopic splenectomy [39].

A number of tests for predicting the likely response to splenectomy have been proposed including response to corticosteroids or IVIg
[45] but these are seldom used as predictors. The best current method for predicting response to splenectomy is the indium-labelled platelet survival scan [46-48]. For patients in whom the platelet destruction is pure or predominantly splenic the chance of a response to splenectomy is around 90\% [49]. Unfortunately this test is only available in a few centres worldwide.

Before carrying out splenectomy patients should be vaccinated against Streptococcus pneumoniae, Haemophilus influenzae and Neisseria meningitidis [3]. These vaccines may not be effective in patients who have received rituximab in the 6 months prior to splenectomy. Following splenectomy patients should be given prophylactic antibiotics such as phenoxymethylpenicillin 250-500 mg twice daily or the equivalent if allergic, possibly for life, although there is no consensus on the exact duration of the prophylaxis. In addition, patients should keep a supply of broad-spectrum antibiotics at home, which they should take if infection is suspected. They are also advised to seek immediate medical attention [50].

With the availability of the TPO-receptor agonists and the long-term responses these may induce one might argue against splenectomy being a valid second-line therapy today. The rate of splenectomy for ITP is falling worldwide and many patients would benefit from deferring splenectomy until they have tried other lines of treatment including TPO-receptor agonist. Unpublished data from the UK Adult ITP Registry have shown a 10\% reduction in splenectomy rates since the publication of the International Consensus document [3]. Even if their platelet count is low it may be safe enough for normal day-to-day living with no requirement for splenectomy. 


\section{THROMBOPOIETIN RECEPTOR AGONISTS}

TPO is the primary factor regulating platelet production [51]. Several TRAs have been developed that activate the TPO receptor and increase platelet production [52-56].

Two drugs, eltrombopag and romiplostim, are currently FDA-approved for use in adult ITP. These second-line agents represent a new class of treatment for ITP. TRAs stimulate megakaryopoiesis, inducing megakaryocyte proliferation and differentiation with an increase in platelet count. From phase I-III trials both drugs are highly effective at raising platelet counts in healthy volunteers and patients with chronic ITP $[57,58]$. This article is based on previously conducted studies and does not involve any new studies of human or animal subjects performed by any of the authors.

\section{ROMIPLOSTIM}

This molecule is an $\mathrm{F}_{\mathrm{C}}$ peptide fusion peptibody. The module consists of a 14-amino-acid peptide dimer covalently linked to two disulphide-bonded human IgG $_{1}$ kappa light chains. This carrier $\mathrm{F}_{\mathrm{C}}$ protein prolongs the half-life of the drug. Romiplostim stimulates megakaryopoiesis after subcutaneous injection. The rise in platelet count is dose-dependent and patients start treatment of $1 \mu \mathrm{g} / \mathrm{kg}$ bodyweight weekly increasing by $1 \mu \mathrm{g} / \mathrm{kg}$ weekly until the desired platelet count is achieved [58].

The initial phase I double-blind placebo-controlled trial involved 48 healthy volunteers [59]. Those receiving romiplostim by single IV injection at $10 \mu \mathrm{g} / \mathrm{kg}$ showed elevated platelet counts at over $1000 \times 10^{9} / 1$. The first study in patients with ITP used a dose of $0.2-10 \mu \mathrm{g} / \mathrm{kg}$ on days 1 and day 15 [52]. Seven of 12 patients at 3,6 or $10 \mu \mathrm{g} / \mathrm{kg}$ achieved a platelet count of greater than $50 \times 10^{9} / 1$. The open dose escalation phase I/II study investigated the safety and efficacy in 16 patients with platelets less than $30 \times 10^{9} / 1$ [60]. Doses between 30 and $500 \mu \mathrm{g}$ were given on days 1 and 15 . Platelet counts of $50 \times 10^{9} / 1$ or greater were seen in all patients. Two parallel phase III studies were carried out in Europe and the USA [55]. Twenty-four of 52 patients were treated with $1 \mu \mathrm{g} / \mathrm{kg}$ or placebo every 7 days with dose adjustment based on platelet counts. One hundred twenty-eight patients were recruited and all of these has severe and refractory ITP. One-third were taking concomitant medication. Sixteen of 42 on romiplostim had a durable response (platelets greater than $50 \times 10^{9} / 1$ for at least 6 out of the last 8 weeks treatment) in the splenectomised group and in 25 of 41 in the non-splenectomised arm. Combining both durable and transient responses 36 out of 41 were seen in the non-splenectomised group and 33 out of 42 in the splenectomised group. There was no recorded risk of thromboembolism in the romiplostim arm [61].

The 12-week study of romiplostim versus placebo was carried out in splenectomised and non-splenectomised Japanese patients with chronic severe ITP [62]. The mean increase in platelet count from baseline was $110 \times 10^{9} / 1$ in those receiving romiplostim compared with $2 \times 10^{9} / 1$ in the placebo arm.

Results are available for up to 5 years continuous dosing involving 292 adults. Platelet counts of greater than $50 \times 10^{9} / 1$ were recorded at least once by more than $95 \%$ of subjects in the study [63]. Ninety-eight per cent experienced adverse events during the follow-up period including headache in 38\%, fatigue in $32 \%$, contusion in 31\%, upper respiratory tract infection in $26 \%$, diarrhoea in 
$25 \%$ and epistaxis in $25 \%$. Nineteen patients experienced 25 thromboembolic events (arterial and venous equally). There was no association with platelet count and only six of these were considered to be related to romiplostim.

Neutralising antibodies to romiplostim were found in two patients (1\%). These antibodies were measured when the patients' platelet counts fell. Antibodies became undetectable after romiplostim was stopped and no cross-reactivity with endogenous TPO was seen.

\section{ELTROMBOPAG}

This is a small molecule of 564.6 Da molecular weight. Eltrombopag is one of the naphthalenesulfonic acids with a potency similar to native TPO [64]. Eltrombopag stimulates megakaryopoiesis in vitro [65]. A phase I study, similar to that of romiplostim, showed a dose-dependent rise in platelet counts [57] and a randomised double-blind placebo-controlled phase II study confirmed both its efficacy and safety [53]. The first phase III study was a 6-week double-blind randomised controlled trial in chronic severe ITP with platelets less than $30 \times 10^{9} / 1$. Eltrombopag showed a response rate of $59 \%$ compared to $16 \%$ with placebo. Common adverse events where non-serious and transient. Deranged liver function tests were seen in some patients.

A 6-month study, RAISE, a randomised controlled double-blind study to evaluate efficacy, safety and tolerability, was conducted [66]. Platelets of over $50 \times 10^{9} / 1$ were seen in 106 (79\%) patients in the eltrombopag arm compared to 17 (28\%) in the placebo arm. Concomitant medication was reduced by $59 \%$ in the eltrombopag arm compared to $32 \%$ in the placebo arm. Rescue medications were reduced with only $18 \%$ in the eltrombopag arm requiring rescue medication compared to
$40 \%$ requiring rescue medication in the placebo arm. The risk of bleeding was $76 \%$ lower in the eltrombopag arm. Thromboembolic events were reported in $2 \%$ of patients ( 0 in the placebo arm). There was a $7 \%$ increase in transaminases in the eltrombopag arm compared to only $3 \%$ in the placebo arm.

EXTEND was an open-label study that recruited patients who had been enrolled in previous eltrombopag studies [67]. A total of 299 patients were treated with eltrombopag for up to 3 years. No new safety issues were reported. Most patients achieved a platelet count response at least once during this period (80\% of splenectomised and $88 \%$ of non-splenectomised). Responses were maintained for a median of 73/104 cumulative weeks for the non-splenectomised arm.

\section{TRAs MAY INDUCE SUSTAINED REMISSIONS}

Romiplostim and eltrombopag are licensed for use in adults with chronic ITP. The drugs stimulate megakaryocyte proliferation and platelet production. The expectation when using these agents is that the platelet count will rise when taking the TRA but will drop to baseline levels when the drug is stopped. These drugs were not licensed with any curative intent. However, published reports show that a proportion of patients may achieve a sustained response to the TRAs even after the drugs have been stopped.

One study of 54 adults treated with at least one TRA over a 5 -year period found that 20 of 28 patients $(28.5 \%)$ who achieved a complete response had a sustained response after stopping the TRA. The median follow-up was 13.5 months. No factors predictive of sustained response were identified [68]. In another study, 46 patients with primary ITP were treated using 
a TRA. Eleven of 46 patients (24\%) were able to stop the TRA (7 romiplostim, 4 eltrombopag) and sustained their platelet counts. Again no predictive factors of sustained response were found [69]. Ghadaki and colleagues reported sustained responses in 9 of 31 patients (29\%) treated with a TRA. Four of the nine patients subsequently relapsed [70]. Provan et al. reported sustained responses after discontinuing romiplostim in 5 of 21 patients (24\%). All patients had received multiple prior therapies. The median duration of the romiplostim administration was 26 months (range 7-60 months). As with previous studies no predictive factors were identified [71]. A more recent phase 2 , single-arm study looked at 75 patients less than 6 months from presentation who had failed first-line treatment and had a continuing platelet count of less than 30 treated with romiplostim [72]. Responses occurred rapidly in more than 90\% and long-term remission occurred in $32 \%$, which were sustained for more than 6 months off all treatment. Again no predictive clinical features could be identified but the studies confirm that a significant proportion of patients can safely stop treatment.

A large series of patients (260) treated with eltrombopag was evaluated by Gonzalez-Lopez and colleagues [73]. Out of 49 evaluable patients, $26(53 \%)$ had a sustained response after stopping eltrombopag with a median follow-up of 9 months.

From the published data, therefore, it would appear that $25-30 \%$ of patients receiving a TRA may expect a sustained response on stopping the drug. The mechanism for these sustained responses is not clear. Some of these patients may have had a spontaneous remission but the patients in all reported studies had received several prior treatments and had severe thrombocytopenia for some considerable time.
Spontaneous remission is therefore unlikely. The TRAs may have an effect on regulatory $\mathrm{T}$ cells (Tregs). These cells naturally suppress autoimmune disease [74]. From studies of rituximab used for the treatment of ITP it would appear that those patients who respond to rituximab normalise their Tregs; those that fail to respond to rituximab do not [75]. The use of the TRAs may have an effect on the Treg compartment returning Tregs to normal number and function, thereby restoring tolerance. However, this has not been confirmed to date.

Alternatively tolerance may be induced by increasing megakaryocyte and platelet mass through the use of TRAs in much the same way as giving large doses of factor VIII is used to induce tolerance in acquired haemophilia.

Clearly more basic science is required in order to determine the underlying mechanism leading to sustained responses in these chronic ITP patients.

\section{CONCLUSION}

Over the past decade, and certainly since the publication of the International Consensus Report [3] and revised American Society of Hematology guidelines [76], there has been a major change in the way ITP is managed. Patients are now treated based on symptoms and signs rather than using an arbitrary platelet threshold. Because of this fewer patients are receiving medical therapies for ITP. Previously used treatments for ITP had low efficacy and considerable side effects for many patients. With the introduction of the TRAs the management of ITP has been transformed. These new agents have very high efficacy and few side effects. The TRAs are effective in even the most refractory patients who can expect to achieve a platelet count that is safe and in many 
cases a normal platelet count. It should be noted, however, that the TRAs should not be used to normalise the platelet count but rather achieve a safe platelet count. After being on a TRA for some time, perhaps a year or 2 , around $25-30 \%$ of patients may achieve a sustained remission with safe or normal platelet counts off therapy. The underlying mechanisms inducing these sustained responses remain to be elucidated.

There are also on-going trials of other treatments with new classes of drugs such as Syk inhibitors (fostamatinib), antibody therapies such as anti-CD40 ligand (anti-CD154), GMA161 (anti-CD16), dacluzumab and alemtuzumab, avatrombopag [77], and others. Once these have been approved for use patients with ITP should expect to have a much higher quality of life because of the low incidence of toxicities and high efficacy of these newer agents with fewer patients receiving the older types of immunosuppressive therapy.

\section{ACKNOWLEDGMENTS}

No funding or sponsorship was received for the publication of this article.

All named authors meet the International Committee of Medical Journal Editors (ICMJE) criteria for authorship for this manuscript, take responsibility for the integrity of the work as a whole, and have given final approval for the version to be published.

During the peer review process, the manufacturer of the agent under review was offered an opportunity to comment on the article. Changes resulting from comments received were made by the author based on their scientific and editorial merit.
Disclosures. DP receives research support from GSK, Amgen and Octapharma. AC has GSK shares, received honoraria from GSK and Amgen, and acted as consultant for Amgen, GSK, Shionogi, UCB and BMS.

Compliance with ethics guidelines. This article is based on previously conducted studies and does not involve any new studies of human or animal subjects performed by any of the authors.

Open Access. This article is distributed under the terms of the Creative Commons Attribution-NonCommercial 4.0 International License (http://creativecommons.org/licenses/ by-nc/4.0/), which permits any noncommercial use, distribution, and reproduction in any medium, provided you give appropriate credit to the original author(s) and the source, provide a link to the Creative Commons license, and indicate if changes were made.

\section{REFERENCES}

1. Stasi R, Provan D. Management of immune thrombocytopenic purpura in adults. Mayo Clin Proc. 2004;79:504-22.

2. Rodeghiero F, Stasi R, Gernsheimer T, Michel M, Provan D, Arnold DM, et al. Standardization of terminology, definitions and outcome criteria in immune thrombocytopenic purpura of adults and children: report from an international working group. Blood. 2009;113:2386-93.

3. Provan D, Stasi R, Newland AC, Blanchette VS, Bolton-Maggs $\mathrm{P}$, Bussel JB, et al. International consensus report on the investigation and management of primary immune thrombocytopenia. Blood. 2010;115:168-86.

4. Neylon AJ, Saunders PW, Howard MR, Proctor SJ, Taylor PR. Clinically significant newly presenting autoimmune thrombocytopenic purpura in adults: a prospective study of a population-based cohort of 245 patients. Br J Haematol. 2003;122:966-74. 
5. Frederiksen $H$, Schmidt $K$. The incidence of idiopathic thrombocytopenic purpura in adults increases with age. Blood. 1999;94:909-13.

6. Schoonen WM, Kucera G, Coalson J, Li L, Rutstein M, Mowat F, et al. Epidemiology of immune thrombocytopenic purpura in the General Practice Research Database. Br J Haematol. 2009;145:235-44.

7. McMillan R, Durette C. Long-term outcomes in adults with chronic ITP after splenectomy failure. Blood. 2004;104:956-60.

8. Cohen YC, Djulbegovic B, Shamai-Lubovitz O, Mozes B. The bleeding risk and natural history of idiopathic thrombocytopenic purpura in patients with persistent low platelet counts. Arch Intern Med. 2000;160:1630-8.

9. Rodeghiero F, Besalduch J, Michel M, Provan D, Grotzinger K, Thompson G. Treatment practices in adults with chronic immune thrombocytopenia-a European perspective. Eur J Haematol. 2010;84:160-8.

10. Provan D, Newland A. Fifty years of idiopathic thrombocytopenic purpura (ITP): management of refractory itp in adults. $\mathrm{Br} \mathrm{J}$ Haematol. 2002;118:933-44.

11. Harker LA, Slichter SJ. The bleeding time as a screening test for evaluation of platelet function. N Engl J Med. 1972;287:155-9.

12. George JN, Woolf SH, Raskob GE, Wasser JS, Aledort LM, Ballem PJ, et al. Idiopathic thrombocytopenic purpura: a practice guideline developed by explicit methods for the American Society of Hematology. Blood. 1996;88:3-40.

13. Portielje JE, Westendorp RG, Kluin-Nelemans HC, Brand A. Morbidity and mortality in adults with idiopathic thrombocytopenic purpura. Blood. 2001;97:2549-54.

14. Provan D. Characteristics of immune thrombocytopenic purpura: a guide for clinical practice. Eur J Haematol Suppl. 2009;8-12.

15. Kitchens CS, Pendergast JF. Human thrombocytopenia is associated with structural abnormalities of the endothelium that are ameliorated by glucocorticosteroid administration. Blood. 1986;67:203-6.

16. Newland AC, Treleaven JG, Minchinton RM, Waters AH. High-dose intravenous IgG in adults with autoimmune thrombocytopenia. Lancet. 1983;1:84-7.
17. Newland AC, Boots MA, Patterson KG. Intravenous IgG for autoimmune thrombocytopenia in pregnancy [letter]. N Engl J Med. 1984;310: 261-2.

18. Cooper N. Intravenous immunoglobulin and anti-RhD therapy in the management of immune thrombocytopenia. Hematol Oncol Clin N Am. 2009;23:1317-27.

19. Mazzucconi MG, Fazi P, Bernasconi S, De Rossi G, Leone $\mathrm{G}$, Gugliotta L, et al. Therapy with high-dose dexamethasone (HD-DXM) in previously untreated patients affected by idiopathic thrombocytopenic purpura: a GIMEMA experience. Blood. 2007;109:1401-7.

20. Cardo LJ, Strack M, Williams J. Anti-D for the treatment of splenectomized patients with immune thrombocytopenic purpura. Blood. 1991;78:2786-7.

21. Cooper N, Woloski BM, Fodero EM, Novoa M, Leber $\mathrm{M}$, Beer JH, et al. Does treatment with intermittent infusions of intravenous anti-D allow a proportion of adults with recently diagnosed immune thrombocytopenic purpura to avoid splenectomy? Blood. 2002;99:1922-7.

22. Vesely SK, Perdue JJ, Rizvi MA, Terrell DR, George JN. Management of adult patients with persistent idiopathic thrombocytopenic purpura following splenectomy: a systematic review. Ann Intern Med. 2004;140:112-20.

23. Quiquandon I, Fenaux P, Caulier MT, Pagniez D, Huart JJ, Bauters F. Re-evaluation of the role of azathioprine in the treatment of adult chronic idiopathic thrombocytopenic purpura: a report on 53 cases. Br J Haematol. 1990;74:223-8.

24. Emilia G, Morselli M, Luppi M, Longo G, Marasca R, Gandini $G$, et al. Long-term salvage therapy with cyclosporin A in refractory idiopathic thrombocytopenic purpura. Blood. 2002;99:1482-5.

25. Kappers-Klunne MC, van't Veer MB. Cyclosporin A for the treatment of patients with chronic idiopathic thrombocytopenic purpura refractory to corticosteroids or splenectomy. Br J Haematol. 2001;114:121-25.

26. Kotb R, Pinganaud C, Trichet C, Lambotte O, Dreyfus M, Delfraissy JF, et al. Efficacy of mycophenolate mofetil in adult refractory auto-immune cytopenias: a single center preliminary study. Eur J Haematol. 2005;75:60-4.

27. Provan D, Moss AJ, Newland AC, Bussel JB. Efficacy of mycophenolate mofetil as single-agent therapy 
for refractory immune thrombocytopenic purpura. Am J Hematol. 2006;81:19-25.

28. Stasi R, Stipa E, Forte V, Meo P, Amadori S. Variable patterns of response to rituximab treatment in adults with chronic idiopathic thrombocytopenic purpura. Blood. 2002;99:3872-3.

29. Arnold DM, Dentali F, Crowther MA, Meyer RM, Cook RJ, Sigouin C, et al. Systematic review: efficacy and safety of rituximab for adults with idiopathic thrombocytopenic purpura. Ann Intern Med. 2007;146:25-33.

30. Cooper N, Stasi R, Cunningham-Rundles S, Feuerstein MA, Leonard JP, Amadori S, et al. The efficacy and safety of B-cell depletion with anti-CD20 monoclonal antibody in adults with chronic immune thrombocytopenic purpura. Br J Haematol. 2004;125:232-9.

31. Ghanima W, Khelif A, Waage A, Michel M, Tjonnfjord GE, Romdhan NB, et al. Rituximab as second-line treatment for adult immune thrombocytopenia (the RITP trial): a multicentre, randomised, double-blind, placebo-controlled trial. Lancet. 2015;385:1653-61.

32. Provan D, Butler T, Evangelista ML, Amadori S, Newland AC, Stasi R. Activity and safety profile of low-dose rituximab for the treatment of autoimmune cytopenias in adults. Haematologica. 2007;92:1695-8.

33. Verlin M, Laros RKJ, Penner JA. Treatment of refractory thrombocytopenic purpura with cyclophosphamine. Am J Hematol. 1976;1:97-104.

34. Reiner A, Gernsheimer T, Slichter SJ. Pulse cyclophosphamide therapy for refractory autoimmune thrombocytopenic purpura. Blood. 1995;85:351-8.

35. Maloisel F, Andres E, Zimmer J, Noel E, Zamfir A, Koumarianou A, et al. Danazol therapy in patients with chronic idiopathic thrombocytopenic purpura: long-term results. Am J Med. 2004;116:590-4.

36. Hernandez F, Linares M, Colomina P, Pastor E, Cervero A, Perez A, et al. Dapsone for refractory chronic idiopathic thrombocytopenic purpura. Br J Haematol. 1995;90:473-5.

37. Yoshida Y. Historical review. The light and shadow of Paul Kaznelson: his life and contribution to hematology. Ann Hematol. 2008;87:877-9.

38. Schwartz J, Leber MD, Gillis S, Giunta A, Eldor A, Bussel JB. Long term follow-up after splenectomy performed for immune thrombocytopenic purpura (ITP). Am J Hematol. 2003;72:94-8.
39. Kojouri K, Vesely SK, Terrell DR, George JN. Splenectomy for adult patients with idiopathic thrombocytopenic purpura: a systematic review to assess long-term platelet count responses, prediction of response, and surgical complications. Blood. 2004;104:2623-34.

40. Vianelli N, Galli $\mathrm{M}$, de Vivo A, Intermesoli $\mathrm{T}$, Giannini B, Mazzucconi MG, et al. Efficacy and safety of splenectomy in immune thrombocytopenic purpura: long-term results of 402 cases. Haematologica. 2005;90:72-7.

41. Johansson E, Engervall P, Landgren O, Grimfors G, Widell S, Rezai $S$, et al. Response to splenectomy is durable after a certain point in time in adult patients with chronic immune thrombocytopenic purpura. Eur J Haematol. 2006;77:61-6.

42. Keidar A, Sagi B, Szold A. Laparoscopic splenectomy for immune thrombocytopenic purpura in patients with severe refractory thrombocytopenia. Pathophysiol Haemost Thromb. 2003;33:116-9.

43. Naouri A, Feghali B, Chabal J, Boulez J, Dechavanne M, Viala JJ, et al. Results of splenectomy for idiopathic thrombocytopenic purpura. Review of 72 cases. Acta Haematol. 1993;89:200-203.

44. Cortelazzo S, Finazzi G, Buelli M, Molteni A, Viero $P$, Barbui T. High risk of severe bleeding in aged patients with chronic idiopathic thrombocytopenic purpura. Blood. 1991;77:31-3.

45. Bussel JB, Kaufmann CP, Ware RE, Woloski BM. Do the acute platelet responses of patients with immune thrombocytopenic purpura (ITP) to IV anti-D and to IV gammaglobulin predict response to subsequent splenectomy? Am J Hematol. 2001;67:27-33.

46. Najean Y, Rain JD, Billotey C. The site of destruction of autologous 111 In-labelled platelets and the efficiency of splenectomy in children and adults with idiopathic thrombocytopenic purpura: a study of 578 patients with 268 splenectomies. Br J Haematol. 1997;97:547-50.

47. Roca M, Muniz-Diaz E, Mora J, Romero-Zayas I, Ramon O, Roig I, et al. The scintigraphic index spleen/liver at 30 minutes predicts the success of splenectomy in persistent and chronic primary immune thrombocytopenia. Am J Hematol. 2011;86:909-13.

48. Cuker A, Cines DB. Evidence-based mini-review: is indium-labeled autologous platelet scanning predictive of response to splenectomy in patients with chronic immune thrombocytopenia? Hematol Am Soc Hematol Educ Program. 2010;2010: 385-6. 
49. Sarpatwari A, Provan D, Erqou S, Sobnack R, David Tai FW, Newland AC. Autologous 111 In-labelled platelet sequestration studies in patients with primary immune thrombocytopenia (ITP) prior to splenectomy: a report from the United Kingdom ITP Registry. Br J Haematol. 2010;151:477-87.

50. Newland A, Provan D, Myint S. Preventing severe infection after splenectomy. BMJ. 2005;331:417-8.

51. Kaushansky K. Thrombopoietin: the primary regulator of megakaryocyte and platelet production. Thromb Haemost. 1995;74:521-5.

52. Bussel JB, Kuter DJ, George JN, McMillan R, Aledort LM, Conklin GT, et al. AMG 531, a thrombopoiesis-stimulating protein, for chronic ITP. N Engl J Med. 2006;355:1672-81.

53. Kuter DJ. New thrombopoietic growth factors. Blood. 2007;109:4607-16.

54. Bussel JB, Cheng G, Saleh MN, Psaila B, Kovaleva L, Meddeb B, et al. Eltrombopag for the treatment of chronic idiopathic thrombocytopenic purpura. N Engl J Med. 2007;357:2237-47.

55. Kuter DJ, Bussel JB, Lyons RM, Pullarkat V, Gernsheimer TB, Senecal FM, et al. Efficacy of romiplostim in patients with chronic immune thrombocytopenic purpura: a double-blind randomised controlled trial. Lancet. 2008;371:395-403.

56. Molineux G, Newland A. Development of romiplostim for the treatment of patients with chronic immune thrombocytopenia: from bench to bedside. Br J Haematol. 2010;150:9-20.

57. Jenkins JM, Williams D, Deng Y, Uhl J, Kitchen V, Collins D, et al. Phase 1 clinical study of eltrombopag, an oral, nonpeptide thrombopoietin receptor agonist. Blood. 2007;109:4739-41.

58. Bussel JB, Provan D, Shamsi T, Cheng G, Psaila B, Kovaleva L, et al. Effect of eltrombopag on platelet counts and bleeding during treatment of chronic idiopathic thrombocytopenic purpura: a randomised, double-blind, placebo-controlled trial. Lancet. 2009;373:641-8.

59. Wang B, Nichol JL, Sullivan JT. Pharmacodynamics and pharmacokinetics of AMG 531, a novel thrombopoietin receptor ligand. Clin Pharmacol Ther. 2004;76:628-38.

60. Newland A, Caulier MT, Kappers-Klunne M, Schipperus MR, Lefrere F, Zwaginga JJ, et al. An open-label, unit dose-finding study of AMG 531, a novel thrombopoiesis-stimulating peptibody, in patients with immune thrombocytopenic purpura. Br J Haematol. 2006;135:547-53.
61. Newland A, Godeau B, Priego V, Viallard J-F, Fernanda M, Fernandez L, et al. Remission rates and platelet responses in patients with immune thrombocytopenia receiving romiplostim: results from a final analysis of a phase 2 , single-arm study. Blood. 2014;124(12):2775.

62. Shirasugi Y, Ando K, Miyazaki K, Tomiyama Y, Okamoto S, Kurokawa M, et al. Romiplostim for the treatment of chronic immune thrombocytopenia in adult Japanese patients: a double-blind, randomized Phase III clinical trial. Int J Hematol. 2011;94:71-80.

63. Kuter DJ, Bussel JB, Newland A, Baker RI, Lyons RM, Wasser $\mathrm{J}$, et al. Long-term treatment with romiplostim in patients with chronic immune thrombocytopenia: safety and efficacy. $\mathrm{Br}$ J Haematol. 2013;161:411-23.

64. Duffy KJ, Darcy MG, Delorme E, Dillon SB, Eppley DF, Erickson-Miller C, et al. Hydrazinonaphthalene and azonaphthalene thrombopoietin mimics are nonpeptidyl promoters of megakaryocytopoiesis. J Med Chem. 2001;44:3730-45.

65. Erickson-Miller CL, DeLorme E, Tian SS, Hopson CB, Stark K, Giampa L, et al. Discovery and characterization of a selective, nonpeptidyl thrombopoietin receptor agonist. Exp Hematol. 2005;33:85-93.

66. Cheng G, Saleh MN, Marcher C, Vasey S, Mayer B, Aivado $M$, et al. Eltrombopag for management of chronic immune thrombocytopenia (RAISE): a 6-month, randomised, phase 3 study. Lancet. 2011;377:393-402.

67. Saleh MN, Bussel JB, Cheng G, Meyer O, Bailey CK, Arning M, et al. Safety and efficacy of eltrombopag for treatment of chronic immune thrombocytopenia: results of the long-term, open-label EXTEND study. Blood. 2013;121:537-45.

68. Mahevas M, Fain O, Ebbo M, Roudot-Thoraval F, Limal N, Khellaf M, et al. The temporary use of thrombopoietin-receptor agonists may induce a prolonged remission in adult chronic immune thrombocytopenia. Results of a French observational study. $\mathrm{Br} \mathrm{J}$ Haematol. 2014;165:865-9.

69. Cervinek L, Mayer J, Doubek M. Sustained remission of chronic immune thrombocytopenia after discontinuation of treatment with thrombopoietin-receptor agonists in adults. Int J Hematol. 2015;102:7-11.

70. Ghadaki B, Nazi I, Kelton JG, Arnold DM. Sustained remissions of immune thrombocytopenia associated with the use of thrombopoietin receptor agonists. Transfusion. 2013;53:2807-12. 
71. Provan D, Taylor L, Nandigham R, Doobaree U, Kalkur P, Newland AC. Sustained responses following treatment with romiplostim in immune thrombocytopenia: a single-centre experience. J Hematol Thromboembolic Dis. 2014;2:147-9.

72. Newland A, Godeau B, Priego V, Valliard J-F, Fernandez MFL, Orejudos A, et al. Remission and platelet responses with romiplostim in primary immune thrombocytopenia: final results from a phase 2 study. Br J Haematol. 2015 (in press).

73. Gonzalez-Lopez TJ, Pascual C, Alvarez-Roman MT, Fernandez-Fuertes F, Sanchez-Gonzalez B, Caparros I, et al. Successful discontinuation of eltrombopag after complete remission in patients with primary immune thrombocytopenia. Am J Hematol. 2015;90:E40-3.

74. Ji X, Zhang L, Peng J, Hou M. T cell immune abnormalities in immune thrombocytopenia. J Hematol Oncol. 2014;7:72.
75. Stasi R, Cooper N, Del Poeta G, Stipa E, Laura Evangelista M, Abruzzese E, et al. Analysis of regulatory $\mathrm{T}$-cell changes in patients with idiopathic thrombocytopenic purpura receiving B cell-depleting therapy with rituximab. Blood. 2008;112:1147-50.

76. Neunert C, Lim W, Crowther M, Cohen A, Solberg LJ, Crowther MA. The American Society of Hematology 2011 evidence-based practice guideline for immune thrombocytopenia. Blood. 2011;117:4190-207.

77. Bussel JB, Kuter DJ, Aledort LM, Kessler CM, Cuker A, Pendergrass KB, et al. A randomized trial of avatrombopag, an investigational thrombopoietin-receptor agonist, in persistent and chronic immune thrombocytopenia. Blood. 2014;123:3887-94. 